\title{
Cristo sin Cristo: \\ religión e idolatría desde las miradas \\ de Edmund Husserl y Simone Weil
}

\author{
Carlo Orellano \\ Pontificia Universidad Católica del Perú
}

Resumen:

La investigación presente analizará las semejanzas y relaciones encontradas entre los planteamientos de Edmund Husserl y Simone Weil respecto al fenómeno religioso de la idolatría. Para ello, señalaremos en primer lugar el tratamiento que la religión podría tener dentro del marco fenomenológico husserliano; posteriormente, nos enfocaremos en el análisis de una de las publicaciones póstumas de autoría weiliana. Respecto al filósofo austríaco, se recurrirá a textos de distintos períodos de su obra, por lo que implícitamente se contemplará una continuación entre sus denominados análisis estáticos y los genéticos.

Palabras clave:

Edmund Husserl, Simone Weil, religión, idolatría, diálogo interreligioso

Abstract: The following research has the aim to stress out the similarities and connections between Edmund Husserl's and Simone Weil's analysis concerning idolatry as a religious phenomenon. In order to achieve it, it will be necessary to analyse how religion could find a place inside Husserl's phenomenological frame; after that, the main focus will lay on the interpretation of one of Weil's posthumous works. Regarding the Austrian philosopher, it is important to point out the fact that a continuum between his static and genetic analyses will be implicitly accepted.

Key words:

Edmund Husserl, Simone Weil, religion, idolatry, interreligious dialogue 
El presente trabajo buscará resaltar las semejanzas entre los análisis que Husserl y Simone Weil hiciesen del fenómeno religioso y, específicamente, de la idolatría. Al ser esta identificada con el dogmatismo o el "anquilosamiento" propio del devenir histórico, como el primero señalará, podremos plantear un paralelo con las ideas que la segunda expusiese en una de sus cartas reeditada hace unos años al castellano.

Debido a que analizar este punto en particular implica pasar previamente por la cuestión de las vivencias religiosas, hecho que requeriría de un análisis mucho más amplio dentro del marco fenomenológico husserliano, señalaremos únicamente los puntos más resaltantes de esta. Para ello, en una primera sección, nos limitaremos a analizar las ideas expuestas en partes de trabajos o manuscritos provenientes del último periodo; fundamentalmente ${ }^{1}$, nos centraremos en La crisis de las ciencias europeas y la fenomenología trascendental' (Husserl 1991), el excurso a sus lecciones sobre ética, recientemente traducidas y agrupadas bajo el título de Introducción a la ética (Husserl 2020) ${ }^{3}$, su ensayo "Tipos formales de cultura en la evolución de la humanidad" (Husserl 2012) ${ }^{4}$ y, finalmente, sus análisis relativos a la percepción y a la memoria (Husserl, 2001)5. En el caso de la segunda autora, el foco de atención recaerá enteramente en su Carta a un religioso (Weil 2011 $)^{6}$, cuyo contenido será contrastado a la luz de la fenomenología de Husserl en un segundo apartado.

1 Los textos a continuación son brindados de acuerdo con el orden en que aparecen en nuestra investigación. Vale decir que mencionamos aquellos a los que recurriremos con mayor frecuencia sin excluir la posibilidad de citar ideas puntuales provenientes de otras obras, las cuales serán referidas oportunamente.

2 En adelante, Crisis. Recurriremos en todo momento a la traducción de Jaboco Muñoz y Salvador Mas

3 En adelante, Excurso. Todas las citas procederán de la edición y traducción de Mariana Chu, Mariano Crespo y Luis Rabanaque. Tanto en esta como en las traducciones de Husserl que lo permitan, se señalarán el tomo y la página de la Husserliana correspondientes.

4 En adelante, Tipos. Traducción de Agustín Serrano de Haro. Debido a que la traducción prescinde de la numeración del tomo del cual procede, la Husserliana XXVII, esta no será incluida como parte de las referencias parentéticas correspondientes.

5 En adelante, Análisis. Las citas procederán de la traducción al inglés de Anthony Steinbock. Para evitar la doble traducción y los problemas que esta podría acarrear, las citas literales no serán volcadas al castellano.

6 En adelante, Carta. Traducción de María Tabuyo y Agustín López. 
Hablar de religión o experiencias religiosas en la fenomenología de Husserl implica tomar en cuenta una serie de ángulos desde los cuales analizarlas. Como señala Steinbock, el fenómeno religioso presenta, en este contexto, una doble dificultad: en primer lugar, excedería lo que normalmente denominaríamos como experimentable, mientras que, en segundo lugar, podría poner de relieve los prejuicios o la manera acaso estrecha como entendemos lo que es, precisamente, "experimentar" algo (Steinbock 2007, 115). Por un lado, el problema podría resultar apremiante por cuanto, al no ser experimentado por todos los sujetos, podría interpretarse como un impedimento para el conocimiento del "mundo de la vida" que subyacería a toda nuestra vida "pre- y extracientífica" (Husserl 1991, §36), hecho que, podría pensarse, anularía la meta de llegar a una ciencia rigurosamente fundamentada:

Tenemos un horizonte mundano como horizonte de posible experiencia de cosas. Cosas: estas son piedras, animales, plantas, también hombres y figuras conformadas por los hombres; pero todo ello es ahí subjetivo-relativo a pesar de que normalmente, en nuestra experiencia y en el círculo social que está ligado con nosotros en una comunidad vital, llegamos espontáneamente a hechos "seguros" [...]. Pero cuando vamos a parar a una esfera de tráfico extraña, entre los negros en el Congo, entre los campesinos chinos, etc., entonces chocamos con el hecho de que sus verdades (esto es, los hechos que para ellos son firmes y que, en general, están acreditados y son susceptibles de acreditación) en modo alguno son las nuestras. Pero si planteamos la meta de una verdad sobre los objetos, verdad que es incondicionalmente válida para todos los sujetos, partiendo de aquello en lo que, a pesar de toda relatividad, coinciden sin embargo los europeos normales, los chinos, los hindúes normales [...] entonces llegamos, en efecto, al camino de la ciencia objetiva (Husserl 1991, §36).

El énfasis en lo que, dentro de cada "comunidad vital", sería considerado "normal" muestra la complejidad del problema, puesto que, aun cuando pudiésemos darnos la libertad de afirmar que es propio de toda religión el sentimiento de algo trascendente, absolutamente inaprehensible a través de conceptos racionales y que está más allá de nosotros (Otto 2016, 47-49), basta con dirigir la mirada hacia nuestra propia cultura para ver que dicha clase de experiencias o, como Otto denomina, "sentimientos" no forman 
parte de la vivencia de todas las personas y, por lo tanto, conducen a que cualquier elucidación posterior resulte incomprensible para muchas de estas (Otto 2016, 52) ${ }^{7}$.

Ante aquel problema, son tres las cosas que pueden ser señaladas para articular una respuesta. En primer lugar, es importante tomar en cuenta el hecho de que, aunque para Husserl fuese la fenomenología aquella que nos condujese propiamente al conocimiento en sentido estricto, la denominada "deconstrucción" que nos permitiría llegar a las "estructuras puras" de nuestra subjetividad (Husserl 2020, 287) no es sino un paso dentro del trabajo filosófico: luego de este, tendría lugar una edificación "rigurosamente científica" desde dichas estructuras hasta llegar a la metafísica como aquella construcción teórica que coronaría la tarea ${ }^{8}$ (Rizo-Patrón 2020, 27). En este sentido, la identificación de fenómenos que no fuesen compartidos por todos los sujetos y que no pudiesen ser explicados a partir de nuestras construcciones teóricas, más que un obstáculo, podría conducirnos a formular con mayor radicalidad la necesidad de "retrotraer[nos] desde los conceptos científicos fundamentales a los contenidos de la 'experiencia pura', enterrar radicalmente todas las presunciones de la ciencia exacta, todos sus peculiares revestimientos mentales" (Husserl 1991, 226).

De esta manera, podría abrírsenos nuevamente la posibilidad de "considerar al mundo como si estas ciencias todavía no existieran, considerarlo precisamente como mundo de vida" (Husserl 1991, 226), gracias a que, como ha sido ya señalado, la experiencia religiosa nos conduciría a someter a cuestionamiento aquello que, por la tradición, se habría "sedimentado"

7 Otto es más enfático al señalar, en referencia al sentimiento religioso de ser criatura o, como él denomina, "lo numinoso", que "[q]uien no logre representárselo o no experimente momentos de esa especie, debe renunciar a la lectura de este libro" $(2016,52)$. Puede plantearse un Ilamativo paralelo con lo que escribiese Freud, coetáneo tanto de Otto como de Husserl, al señalar que, pese a haber tomado conocimiento de aquel "sentimiento de eternidad" u "océanico" por parte de un amigo cercano, él se veía en la imposibilidad de descubrir dicho sentimiento dentro de sí $(2010,58)$.

8 Resulta importante señalar que esta construcción teórica tendría un carácter probable y no definitivo, ya que no tendría validez para todos los sujetos, tal como hemos señalado previamente. Podemos mencionar, a manera de ejemplo, lo que ocurre respecto al fenómeno místico, cuya vivencia es comprendida de maneras distintas de acuerdo a cada "contexto vital", lo que le brinda al término un carácter polisémico (Martín 2003, 17). 
en "presupuestos permanentes de [nuestras] estructuras, ideas, proposiciones, teorías", cuestiones con las cuales podríamos, sin que nos percatemos de ello, estar encubriendo el mundo, tal como habría ocurrido con Galileo (Husserl 1991, 54). Todo esto se encuentra, vale decir, en consonancia con la inversión que realizase Husserl entre "los significados tradicionales [de] filosofía primera y segunda" (Rizo-Patrón 2018, 107) al destacar a la fenomenología trascendental como la piedra angular a partir de la cual, de manera ascendente y tras realizarse la deconstrucción previamente mencionada, podrían elaborarse planteamientos metafísicos plausibles sobre la base de la evidencia obtenida (Rizo-Patrón 2018, 120).

Esto nos conduce al segundo de los puntos que tendrían que ser analizados: la naturaleza de aquello de lo cual buscamos evidencia, la divinidad. Así, uno de los problemas al momento de abordar el fenómeno religioso dentro de la propuesta husserliana, tal como habría identificado García-Baró, es el hecho de que esta última, al partir de la experiencia del sujeto, la cual es siempre "finita y admite grados", podría abandonar la idea de que la realidad tenga una dependencia ontológica con lo divino (Rizo-Patrón 2018 , 108). Ante este asunto, que podrá ser analizado solo sumariamente, valdría hacernos la pregunta de qué estamos entendiendo por "Dios" o, en general, por "divinidad": si bien toda experiencia de esta tendría que darse dentro de nuestra vivencia subjetiva, por lo cual lo divino se vería reducido a un nóema o sentido predicativo (Rizo-Patrón 2018, 109), ello no implica que aquel no pueda ser reformulado y, más aún, que en medio de esa reformulación no pierda su carácter trascendente. Si asumimos, entonces, que el sujeto, dentro de su finitud, tiene la posibilidad de entrar "en relación y en diálogo con el Absoluto" o Dios (Rizo-Patrón 2018, 112), esto implicaría el que pudiese, de alguna forma, trasgredir su propia finitud para llegar a una fuente infinita o indeterminada. Curiosamente, es posible encontrar en los textos de Husserl pistas que nos encaminen hacia la reformulación de dicha relación, para la primera de las cuales nos remitiremos a la quinta de sus Meditaciones cartesianas.

Así, en el mencionado texto, Husserl señala explícitamente el hecho de que el reconocer a otro sujeto como tal implica una "transgresión intencional" (Husserl 2006, 149): "transgrede" nuestra experiencia subjetiva por 
cuanto no se trata de un proceso meramente lógico, de una inferencia o de una inducción, así como tampoco se trata de dotar a un objeto de un determinado sentido, ya que, al reconocerlo como otro sujeto o como un "alter ego" (Husserl 2006, 150), estamos identificando en él un núcleo de vivencias íntimas que no podríamos vivir en primera persona y que, por lo tanto, podemos conocer únicamente de manera mediata o "impropia", ello sin dejar de reconocer el hecho de que haya un "yo" al cual dichas vivencias sí le son dadas de manera originaria (Husserl 1991, 227-228).

Para complementar lo anterior, valdría señalar que dicho núcleo no se encontraría únicamente en nosotros como sujetos, sino que, en tanto podríamos ser tematizados como objetos toda vez que se predique algo de nosotros, podríamos hallarlo también en los objetos que nos rodean en general:

Si decimos tan solo "la casa", "la mesa", el sentido ya nos remite a los juicios originarios determinantes: "esto es una casa", "esto es una mesa". Retrocediendo de este modo, finalmente llegamos a posiciones de objeto realmente primitivas, cuyos objetos son aún indeterminados, como lo son todos los objetos de experiencia. Pero los objetos que han acogido en su sentido determinaciones predicativas se llaman objetos de pensamiento u objetos de conocimiento, poseen un núcleo "indeterminado" y un estrato de conocimiento, un sedimento de la esfera del saber. (Husserl 2020, 273).

Sin ignorar el que resulte necesario distinguir entre las formas de predicación vividas cuando nos encontramos frente a un objeto y cuando nos encontramos frente a un sujeto reconocido como tal, lo importante de este análisis es destacar el hecho de que, tanto en una forma como en la otra, nos hallamos ya ante la trascendencia del mundo y de todo lo que en él encontramos. Si retornamos a la quinta Meditación, vemos que, aunque el mundo se erija siempre sobre el "mundo primordial" que cada uno vive en primera persona y de forma originaria, aquel incluirá también un grado de constitución proveniente "del otro o de los otros en general, esto es, de los egos excluidos de mi concreto ser propio" (Husserl 2006, 142). En conexión con la transgresión intencional explicada líneas arriba, podemos concluir que la constitución misma del mundo implica una transgresión de mi esfera puramente individual. En palabras de Held, la "limitación a la 
respectiva experiencia subjetiva del mundo del individuo es eliminada por la trascendencia de lo objetivo" (Held 2011, 13-14), con lo cual el diálogo entre el individuo y aquello que lo trasciende podría bien entenderse como el diálogo entre el individuo y los múltiples otros individuos, quienes, en tanto que sujetos, resultan igualmente inagotables e inaprehensibles en su totalidad, y junto a quienes se habría constituido o se podría constituir intersubjetivamente un mundo igualmente inagotable ${ }^{9}$.

Los análisis previos nos conducen al último y más importante punto de esta sección: aquel que nos permitirá conocer, desde la postura de Husserl, las condiciones de una vivencia religiosa genuina de aquella que, al no serlo, podríamos calificar de "idolatría". Vale señalar, con Steinbock, que con este término no debe entenderse un acto o rituales en específico, sino, por el contrario, el sentido que brindamos a dichos actos y la fuente de la cual provendría. Así, para este intérprete, la idolatría puede definirse en términos de "self and pride", "the attachment to 'world', which is expressed in both secularism and fundamentalism" $\mathrm{y}$ "the mono-dimensional character of experiences" (Steinbock 2007, 212).

A grandes rasgos, el núcleo de estas tres características podría ubicarse en el pasar por alto el hecho de que, aunque "el yo y el objeto se hall[e]n en una referencia a priori", son distintos y se distinguen también de la proposición o el acto y de los sentidos mentados o expresados en ellos (Husserl 2020, 261). En otras palabras, la religión se tornaría idolatría cuando tomamos nuestra perspectiva, sea individual o sea aquella que compartimos con

9 Todo esto debe de ser leído a la luz de lo expuesto por Husserl en sus discursos relativos al ideal de la humanidad de Fichte. Como el filósofo menciona allí, una de las cuestiones que más destaca de Fichte es el hecho de que hubiese barrido con "the affecting things-in-themselves and pronounced that they were the last remnant of a naive dogmatism" (Husserl 1995, 116) o, en términos kantianos, el haber descartado el postulado de un noúmeno. De acuerdo con esta tesis, a la cual Husserl se adhiere, no tendría sentido buscar demostrar cosas que no estuviesen en relación con la subjetividad; por ello, si Dios, la inmortalidad o la libertad han de ser tomadas como existentes, su trascendencia no podría ubicarse en algo que estuviese "más allá" del mundo, sino que, por el contrario, tendría que hallarse en nuestro interior: "Therefore the human must have behind his being (Sein) as phenomenon a transcendent essence (Wesen) and a transcendental freedom" (Husserl 1995, 116). Todo esto guardará armonía, como señalaremos más adelante, con lo que Husserl expusiese respecto a la religión y la necesidad de que esta, para ser verdad, implique una contemplación de la divinidad dentro de sí (Husserl 2012, 72). 
nuestra comunidad, como la única perspectiva legítima frente al fenómeno religioso; de ahí, que Steinbock pueda calificar ambas cuestiones como provenientes de una visión "mono-dimensional" o de lo que tradicionalmente es traducido como "soberbia"10. Retomando las ideas de Husserl citadas, el error del idólatra radicaría en identificar el sentido dado al objeto con el objeto mismo o al tomar determinados actos, sean rituales o de otro tipo, como los únicos correctos en lo referente a la divinidad.

El asunto se agrava si tomamos en consideración la mención del "yo" (self) y del "mundo": igual de incomprensible resultaría la experiencia religiosa de un otro o, en general, de otra comunidad vital si nos desenvolvemos exclusivamente tanto dentro de una "aproximación objetivista de la ciencia" como de "su hijuela —la imagen 'objetivada' de la subjetividad" (Rizo-Patrón 2020, 36). Ambas cuestiones nos impedirían reconocer el rol constitutivo de la subjetividad, al reducirla, como la famosa frase de Husserl señala, a estar conformada meramente por hechos y a ser mero producto de hechos ${ }^{11}$, a la vez que negaría la multiplicidad de vivencias pasibles de ser encontradas en el mundo:

En la matematización geométrica y científico-natural ceñimos, pues, el mundo de vida - el mundo que nos es dado permanentemente como real en nuestra vida mundanal concreta-, en la abierta infinitud de las experiencias posibles, con un ajustado ropaje de ideas, el de las llamadas verdades científico-objetivas. [...] El ropaje de ideas que conocemos como "matemática y ciencia natural matemática", o incluso el ropaje de símbolos de las teorías matemático-simbólicas, cubre - tanto para el científico como para los hombres cultos- todo cuanto asumido como naturaleza "objetiva, real, verdadera" ocupa el lugar del mundo de vida, lo disfraza. (Husserl 1991, 53) $)^{12}$

10 En el sentido que, teológicamente, adquiriese el término hybris o su traducción latina, superbia.

11 "Meras ciencias de hechos hacen meros hombres de hechos" (1991, 6).

12 Un claro ejemplo de esta manera de cubrir toda vivencia ajena con lo que nosotros pudiésemos considerar "verdadero" puede hallarse en el caso de la patrona de nuestra casa de estudios, Rosa de Lima. Al lado de las investigaciones realizadas en torno al sentido que, para una religiosa de su época y de su localidad, pudiesen haber tenido los distintos actos de piedad y las experiencias místicas que manifestase, así como la valoración que la sociedad de su tiempo les diese (Cfr. M. Guerra \& E. Guerra 2017), es posible hallar profusos intentos de interpretar su vida en términos médicos o, específicamente, psiquiátricos. Consecuentemente, no faltará quienes, desde un punto de vista "científico", la tilden fácilmente de esquizofrénica o, lo que resulta aun más problemático, vean su vida como un mero producto o consecuencia 
Lo anterior cobra mayor sentido en referencia al fenómeno religioso si tomamos en cuenta el hecho de que este, como todo otro fenómeno, no está exento de cambiar de validez ante los sujetos con el paso del tiempo, de sedimentarse y verse "vaciada" de su sentido intuitivo originario (Husserl 1991, 50):

Cuando la religión en contra de sus promesas ya no trae salvación a la nación, ni tampoco, por tanto, salvación personal; cuando la explicación inicialmente iluminadora [...] pierde su vigor; cuando tras el castigo soportado con resignación y las expiaciones más y más duras, aún crece el sufrimiento; cuando todo ello ha ocurrido ya, se dan las condiciones para una toma de postura más libre respecto de la tradición y del anquilosamiento tradicionalista que es producto inevitable del desarrollo histórico. El individuo y miembro del pueblo que anhela su salvación, repiensa para sí de nuevas (sic.) su relación personal para con su Dios [...] (Husserl 2012; cursivas añadidas).

La religión perdería su verdadero sentido, entonces, cuando se buscan fijarse en el tiempo los sentidos particulares, los actos u objetos constituidos por esos sentidos y los sujetos que habrían vivido dicho sentido como "revelación", restándole así al fenómeno religioso el dinamismo que le sería inherente como fenómeno histórico y negándole al sujeto "la facultad crítica [que] pertenece a [su] esencia" (Husserl 2012, 70). Por el contrario, reconocer que la libertad y la crítica que conlleva no se oponen a la fe, sino que llevan a complementarla y transformarla en "religión de la fe libre, de la fe racional, en lugar de serlo de la tradición ciega", conduciría a su "sano progreso [...] en diferenciación progresiva" y al enriquecimiento de su "núcleo de valores" (Husserl 2012, 71).

causal: "necesariamente tuvo que haber tenido en su historia una forma de abuso psicológico, sexual o físico" (Aweita 2018; cursivas añadidas). Por un lado, esto ilustra perfectamente lo que Husserl ya hace un siglo advirtiese: "El naturalismo psicológico, que domina la época moderna y que se inicia ya en sus comienzos con el materialismo de Hobbes, entiende la vida anímica enteramente como un campo de la causalidad natural" (Husserl 2020, 294-295). Por otro lado, resulta interesante para nuestro trabajo complementar lo anterior compartiendo la afirmación de Gray: las visiones naturalistas actuales no solo han "inspirado numerosos credos laicos" (Gray 2018, 36), sino que, de manera explícita, habrían formado parte del itinerario de Comte. Este, inspirado en Saint-Simon, se habría planteado expresamente la meta de que los sacerdotes fuesen "sustituidos por los científicos como líderes espirituales", además de haber esperado elaborar una hagiografía basada en "figuras como Arquímedes y Descartes" (Gray 2019, 20-21). Es, pues, de esta manera como se entiende que Steinbock colocase a la secularización a la par del fundamentalismo en su análisis de la idolatría. 
Todo esto resulta deseable desde la óptica de Husserl debido a que ello permitiría que el ser humano se cultive "crecientemente a sí mismo", convirtiendo el "núcleo racional" en "la piedra angular de toda la fe" (Husserl 2012,72 ). Podemos extrapolar el asunto y señalar que, tal como podríamos hablar de una crisis en las ciencias al identificar que estas han perdido su "cientificidad genuina" (Husserl 1991, 3) o al notar que tomamos "por ser verdadero lo que es un método" (Husserl 1991, 53), sería posible identificar también "una crisis en la religión" (Tipos, 72) cuando caemos en la "attitude of self-forgetfulness" (Husserl 2001, 594) y, más allá de reconocer nuestra deuda con el pasado y afirmar que "we do not actually view, we do not actually perceive, we do not actually have modes of appearance as actual ones" (Husserl 2001, 593), quedamos irreflexivamente sumergidos o perdidos en él:

But when we were submerged, we were precisely not coming on the scene as the actual ego actively occupied now; we were dreaming, and making its appearance was only the dreamt memorial ego of the past. (Husserl 2001, 595)

Este olvido del momento presente, de la necesidad de basarnos en "conocimiento auténtico" extraído de evidencia inmediata (Husserl 2012, 84) está, como venimos señalando, presente en la vivencia religiosa: en esta, podemos toparnos con convicciones aparentemente objetivas, que en realidad se fundan únicamente en el hecho de estar "profundamente arraigad[a]s" en nosotros, al punto de que "su sola puesta en duda amenaza con 'desarraigar' a la persona; y esta cree no poder suprimirlos sin suprimirse a sí misma, lo que puede conducir a reacciones virulentas de ánimo" (Husserl $2012,85)$. Es el cuestionamiento de estas convicciones el que nos permitiría abrirnos a la multiplicidad de vivencias religiosas, fundadas, como argumentásemos previamente, en la constitución intersubjetiva del mundo, a la vez que contribuiría a la "autorreflexión y autorresponsabilidad" propias del desarrollo de un "Yo verdadero, libre, autónomo", al que les innata la razón (Husserl 1991, 280) tanto como le es necesario el reconocerse parte de una "comunidad yoica" (Husserl 1991, 278) ${ }^{13}$.

13 Cabe no pasar por alto el hecho de que la necesidad de esta autorreflexión está presente no solo en la Crisis, sino también en el Excurso y en Tipos. En el caso del primero, encontraremos 
Las semejanzas que pueden trazarse entre Simone Weil y la fenomenología de Husserl son varias y, en caso aquella no hubiese tenido acceso directo a los escritos de este, dichos puntos de encuentro podrían deberse a la recepción que hiciesen del pensamiento husserliano los existencialistas franceses de los cuales Weil fuese contemporánea. Dejando de lado, debido a que escapan a la presente investigación, las diferencias entre el pensamiento de esta filósofa y los pensadores existencialistas de su tiempo, podríamos centrarnos en las similitudes mencionadas inicialmente refiriendo el hecho de que aquella habría concebido como condición necesaria el que toda "reflexión filosófica deb[a] realizarse a partir de la vida misma" (Godina 2011, 215). Esto se ve bellamente ilustrado en el fragmento de una de sus cartas, redactada en 1941:

Platón decía que la vista es verdaderamente valiosa porque nos hace conocer las estrellas, los planetas, la luna, el sol. Por mi parte me avergüenza decir que apenas conozco las constelaciones y sus nombres. Hace algunos meses me procuré un planisferio para acabar con mi ignorancia, pero no lo estudié porque pensé después que no necesitaba libros para mirar el cielo y que mirándolo a menudo y durante mucho tiempo puedo llegar a reconocer sin ayuda los grupos de estrellas y el movimiento del cielo como los pastores que inventaron la astronomía hace miles de años (Weil, citada en (Godina 2011, 216).

El fragmento anterior es significativo en virtud de la idea medular que expresa: a pesar de su amor por Platón, por la filosofía y por la cultura antiguas, plasmado en otras de sus obras, pone de relieve el hecho de que, por encima de cualquier elaboración teórica — fuese filosófica, fuese científica

una aclaración que podría echar luces al denominado proceso de "anquilosamiento": cotidianamente, nos encontraríamos con proposiciones "unirradiales" o, en apariencia, "primitivas", las cuales surgirían de una nominalización de "proposiciones judicativas", "determinantes" o, podríamos decir, predicativas en general. Así, siguiendo los ejemplos del autor, tendríamos oraciones plurirradiales del tipo "el tiempo está nublado", las cuales podrían convertirse en la expresión unirradial "el tiempo nublado" (Husserl 2020, 273, [Hua XXXVII, 275-276]). Esto, podemos inferir, podría llevarnos a olvidar con el tiempo la atribución realizada y tomar el objeto referido junto con su sentido como un todo. Una idea asimilable a la anterior es la que aparece en el segundo de los textos, donde se plantea la distinción entre los "juicios motivados con evidencia mediata", los cuales se basarían en inferencias, y los "juicios sujetos a norma con evidencia inmediata", los cuales se basarían en lo que "la cosa" muestra "originaliter" (Husserl 2012, 84). 
en relación al "planisferio"—, cobraba más importancia la observación en primera persona. Esta observación, vale aclarar, no quedaría en un mero deleite de lo que llega a la vista, sino que, tal como señalan las líneas finales, conduciría a un encuentro con lo que Husserl denominaría la "evidencia originaria", la "vida originariamente intuitiva" previa a toda formulación lingüística y al posterior desencanto que estas formulaciones podrían conducir (Husserl 2000, 40).

Esto sería compatible con dos de los objetivos transversales al pensamiento de Weil: por una parte, su preocupación por "despojar el pensamiento y la acción de las adhesiones idólatras que desvían su vocación" (Godina 2011, 217), mientras que, por otra parte, el énfasis que pondría en el desarrollo de la virtud que ella denominaría "atención" (Godina 2011, 218). Esta sería, consecuentemente, una "facultad que se puede formar"y nos permitiría"no tener una mirada con sombras" para, sin olvidar el que toda reflexión parta de nuestra experiencia subjetiva, permitirnos pensar y escuchar al otro en su alteridad tanto como nos resulte posible. Esto, podemos interpretar, nos permitiría cultivar una civilización "que atienda a la vida y no a la muerte": no tomaría a los otros como objetos y, en ese sentido, como cosas inertes o "muertas", sino que, al atender a lo que tienen que decir y permitirnos ser interpelados por ello, los tomaría propiamente como sujetos vivos y, de esa forma, despertaría la responsabilidad que tendríamos hacia ellos (Godina 2011, 222):

Hablar de atención creadora en [Simone Weil] es, entonces, abrirse al mundo y su acontecer diario, darse tiempo para mirar, escuchar, dejar de pensar en primera persona ${ }^{14}$ para implicarse en los problemas del otro [...]. Cuando dejamos que este silencio, que este vacío nos posea, podemos aprender a escuchar otras palabras, palabras no vacuas, no carentes de significado sino que tengan sentido [...]. Estar atento es estar vigilando prácticamente el acontecer social (Godina 2011, 217).

14 Si bien las limitaciones de la presente investigación no nos permiten contrastar esta afirmación con otros textos weilianos, habría que entender este "dejar" la primera persona no en términos absolutos, sino en el sentido de hacerlo en la medida en que resulte posible. De no entenderlo de esa manera, estaríamos cayendo, junto con la intérprete citada, en una contradicción. 
A partir de lo anterior, vemos que la atención se constituye como punto central de la praxis de Simone Weil, la cual no dejaría de lado el aspecto religioso con el que la filósofa tiñese todo este proceso: “Esa vocación por la alteridad hace de ella una mística de la entrega" o, como posteriormente se afirmaría, "una mística de ojos abiertos [...] que le permite[n] atender la realidad del mundo" (Godina 2011, 220).

La cuestión de la alteridad o de la apertura resultará importante tanto en sus planteamientos religiosos como políticos ${ }^{15}$. Ciñéndonos en esta investigación a los primeros, nos remitiremos a la carta que dirigiese a un religioso católico a inicios de la década del 40, acción realizada con el objetivo de aclarar si, desde los dogmas manejados por la Iglesia, le sería posible su adhesión a ella, sea sin abandonar los planteamientos de los que pudiese haber brindado un fundamento correcto, sea abandonando aquellos que se le mostrasen como incorrectos. Vale señalar que, en dicho texto, el cuidado con el cual son tratados tanto el fenómeno religioso en general como las manifestaciones religiosas de otras culturas presenta distintos aspectos que permiten aproximar su postura hacia el marco fenomenológico husserliano expuesto en la sección anterior.

Respecto al primero de los puntos, una cuestión que capta inmediatamente la atención es el llamado que la filósofa hace a no afirmar categóricamente nada en relación a lo sagrado (Weil 2011, 17): si bien dará afirmaciones acerca de las acciones o interpretaciones dadas a los textos considerados sagrados siempre que se alejen de la bondad o la "caridad evangélica" (Weil 2011, 18), reconocerá la imposibilidad de dar una afirmación última acerca de la divinidad de acuerdo a lo que ella denomina su “imperfección” (Weil 2011,

15 Al respecto, valdría remitirnos a su texto "No empecemos otra vez la guerra de Troya" (Weil 2007) y a su artículo periodístico titulado Nota sobre la supresión general de los partidos políticos (Weil 2014). En el primero de estos, señala, basándose en la versión del rapto de Helena de acuerdo con el cual a Paris le fue entregada nada más que una copia de la verdadera, el hecho de que, bajo el nombre de distintos partidos o frentes políticos, se instiguen luchas sociales o enfrentamientos en general sin que nos percatemos previamente si acaso aquello por lo cual luchamos no es más que una mera ilusión o una palabra completamente vacía. Esta misma idea se relaciona con el segundo de los textos, en el cual, más que señalar el carácter ilusorio que estaría presente en las divisiones partidarias, se hace énfasis en las formas como estas terminan impidiendo el libre pensamiento de sus miembros, fomentando el sectarismo y, en conclusión, obstaculizando lo que ella denomina una verdadera democracia. 
15) o, como podríamos interpretar, su finitud. Aun cuando las afirmaciones acerca de la divinidad no vayan a estar del todo ausentes, como ocurrirá cuando, más adelante, afirme que "la verdad esencial" es que "Dios es el Bien" (Weil 2011,28), resulta interesante para nuestro análisis el destacar la consecuencia metodológica que Weil extrae de lo primero: la necesidad de una "suspensión del juicio respecto a todos los pensamientos, cualesquiera que sean, sin excepción" (Weil 2011, 17). En esto radicaría "la virtud de la humildad en el dominio de la inteligencia" (Weil 2011, 17), elementos que, nuevamente, podrían ser interpretados a la luz de la finitud del sujeto en relación a las experiencias religiosas discutidas anteriormente.

Posteriormente, y casi de inmediato, su texto nos enfrenta con lo que ella claramente define como idolatría:

Lo que llamamos idolatría es en gran medida una ficción del fanatismo judío. Todos los pueblos de todos los tiempos han sido siempre monoteístas. Si los hebreos de aquella época resucitaran, y si les dieran armas, nos exterminarían a todos, hombres, mujeres y niños, por el crimen de idolatría. Nos reprocharían adorar a Baal y Astarté, tomando a Cristo por Baal y a la Virgen por Astarté. Recíprocamente, Baal y Astarté eran quizá figuras de Cristo y de la Virgen (Weil 2011, 19; cursivas añadidas) ${ }^{16}$.

Las cursivas agregadas a la cita anterior ponen de relieve el método que la filósofa seguirá a lo largo de todo su escrito: el hecho de no aferrarse a las imágenes ni provenientes de la propia tradición en la que se mueve, la judeo-cristiana, ni de aquellas provenientes de otras culturas. Respecto al catolicismo específicamente, señalará que fijarnos en la cronología de un suceso es una "superstición" de la cual hemos de deshacernos si buscamos realmente acceder a Dios o, como ella lo llama, la "Eternidad" (Weil 2011, 42). Afirmar que un hecho histórico milagroso tuvo efectos en nuestra manera de entender la religión traerá, a decir de Weil, como mínimo el siguiente problema:

16 Es imperativo no perder de vista el hecho de que la filósofa aclare que se refiere a los judíos "de aquella época" para no interpretar este pasaje como una señal de antisemitismo. Por el contrario, la total repulsión a esta postura, personificada en Hitler, queda tajantemente marcada cuando afirma que "Hitler podría morir y resucitar cincuenta veces y para mí no sería el hijo de Dios" (Weil 2011, 47). 
Afirmar que los milagros cristianos son los únicos auténticos y todos los demás son falsos, o que son los únicos provocados por Dios y todos los demás por el demonio, es un recurso miserable. Pues es una afirmación arbitraria, y desde ese momento los milagros no demuestran nada; ellos mismos tienen la necesidad de ser demostrados puesto que reciben de fuera un sello de autenticidad (Weil 2011, 44).

A partir de este punto, podemos comenzar a trazar vínculos con lo que expuesto respecto al planteamiento husserliano: presenciamos construcciones teóricas, posiblemente elaboradas sobre la base de una vivencia originaria a modo de revelación, que, sin embargo, han venido anquilosándose al punto de desencadenar las "reacciones virulentas del ánimo" que el fenomenólogo señalase (Husserl 2012, 85). El fenómeno religioso, en consecuencia, habría venido recubriéndose de elaboraciones teóricas al punto de perder contacto con su fuente experiencial primera.

Si bien la filósofa no dará una solución al problema de manera explícita, este puede ser extraído a partir de una serie de afirmaciones presentes en su escrito. Esto se hace patente al recurrir al método que, como señalamos párrafos arriba, sería llevado a lo largo de la Carta: las imágenes provenientes de otras culturas, aun cuando se trate de sociedades "cronológicamente pre-cristianas", tendrían que ser juzgadas por los valores que encarnaron para interpretar si se trató de culturas que eran "cristiana[s] en su esencia" (Weil 2011, 23).

Este proceso será llevado ampliamente por Weil al interpretar diversos elementos presentes en el Nuevo Testamento como relaciones entre Cristo y las divinidades precedentes: el vino transformado en las bodas de Caná será visto como la manera en que Cristo, expresamente, habría trazado una conexión entre sí mismo y Dionisio, cuestión que se vería reforzada por su afirmación "Yo soy la vid verdadera" (Weil 2011,24). Asimismo, el aceite procedente del fruto del olivo, árbol consagrado a Atenea, sería visto también como un vínculo entre el cristianismo y esta divinidad en lo referente a los sacramentos, al punto de ver una fuerte afinidad entre esta diosa y el Espíritu Santo: aquella, al proceder de la cabeza de Zeus y portar su sabiduría, nos conduciría hacia él tal como el Espíritu Santo nos conduciría hacia el Padre (Weil 2011, 23). 
Ejemplos como este abundan, tales como ver en el pan de la última cena la presencia de Deméter y de la celebración eucarística entera como una nueva versión de los antiguos misterios griegos (Weil 2011, 21-22), la relación entre la Virgen y la chorá sobre la que Platón escribiese en su Timeo (Weil 2011 , 24), la relación entre la crucifixión de Cristo y la muerte por la horca a la que Odín se sometiese voluntariamente en Yggdrasil, el árbol cósmico de la religiosidad nórdica (Weil 2011, 24), etc. Ante todo esto, no obstante, sería natural formular dos objeciones para las cuales, es necesario admitir, no faltarían razones: en primer lugar, ¿qué es lo que permite a Simone Weil afirmar, como se ve en las citas previas, que todas las religiones han sido siempre monoteístas? ¿No va esto en contra de lo que la misma evidencia proveniente de otras culturas muestra y, peor aun, no es esto muestra de que la filósofa no está haciendo más que volcar sus propios prejuicios como cristiana ${ }^{17}$ ? En segundo lugar, y en estrecho vínculo con la última interrogante, ¿no se hacen completamente evidentes sus prejuicios al señalar que determinadas manifestaciones religiosas habrían sido cristianas en esencia y, por lo tanto, no estaría cayendo ella misma en la idolatría que tan arduamente critica?

Ante estas objeciones, pueden plantearse dos respuestas a partir de la Carta misma. En primer lugar, hay que tener en cuenta lo señalado al inicio de la presente sección: Weil nunca habría perdido de vista la necesidad de fundar toda reflexión filosófica en su vivencia personal. Esto implica el hecho de que todo contacto con la divinidad no solo se da en primera persona, sino que se da en términos de la tradición o la historia en las cuales dicha subjetividad ha ido constituyendo su mundo. En ese sentido, la filósofa señalará enfáticamente:

17 Resulta pertinente aclarar que, pese a las duras críticas dirigidas a la Iglesia, la filósofa no habría dudado de su fe. Tal como señala, de no ser sus pensamientos infundados y de obligársele a abandonarlos únicamente por la fuerza del dogma o de la autoridad (particularmente, del concilio de Trento, con el cual manifiesta su entera disconformidad), ella llega a la conclusión de que su "vocación es ser cristiana fuera de la Iglesia. La posibilidad de tal vocación implicaría que la Iglesia no es tan católica de hecho como lo es de nombre, y que deberá serlo algún día, si está destinada a cumplir su misión." (Weil 2011,17) 
Siempre que un hombre ha invocado con un corazón puro a Osiris, Dioniso, Krishna, Buda, el Tao, etc., el Hijo de Dios ha respondido enviándole el Espíritu Santo. Y el Espíritu ha actuado sobre su alma, no instándole a abandonar su tradición religiosa, sino dándole luz - y en el mejor de los casos la plenitud de la luz-en el interior de esa misma tradición (Weil 2011, 29-30; cursivas añadidas).

El Espíritu Santo, recordemos, no es únicamente la entidad católica o cristiana: como hemos visto previamente, es también Atenea, de la misma forma como, en otros pasajes, se nos señala que Osiris, Prometeo e, inclusive, figuras dentro de la misma tradición abrahámica como Noé, podrían haber sido Hijos de Dios tal como Cristo lo fue (Weil 2011, 22-23, 29). A esto es necesario añadir que, en palabras de Weil, "[c]uando Cristo dijo: 'enseñad a todas las naciones y llevadles la noticia', ordenaba transmitir una noticia, no una teología" (Weil 2011, 30). En consonancia con esto, Weil afirmará que el afán misionero de la Iglesia habría comprendido en un sentido radicalmente erróneo las palabras de Cristo, con la conclusión de haber llevado no más que "horribles crueldades" y de haber buscado desenraizar y destruir los diversos pueblos a los que habría llegado, incluido el mismo continente europeo (Weil 2011, 31):

Personalmente, jamás daría ni veinte céntimos para una obra misionera. Creo que el cambio de religión es para cualquier ser humano algo tan peligroso como para un escritor el cambio de lengua. (Weil 2011, 32)

Finalmente, la filósofa no habría negado las dificultades implícitas en la comprensión de una vivencia religiosa distinta de la propia:

San Juan de la Cruz compara la fe a los reflejos de la plata, siendo la verdad el oro. Las diversas tradiciones religiosas auténticas son reflejos diferentes de la misma verdad, y quizá igualmente valiosas. Pero no nos damos cuenta, porque cada cual vive una sola de esas tradiciones y percibe las otras como algo que está fuera. Ahora bien, como los católicos repiten sin cesar, y con razón, [...] una religión solo se conoce desde dentro (Weil 2011, 33; cursivas añadidas).

De este modo, vemos en Weil una postura, propia tanto de la fenomenología como de la hermenéutica, que reconoce que "el hombre conoce el mundo siempre como una interpretación, pues no puede decir cómo son las cosas 
en sí mismas desde un lugar privilegiado y atemporal" (Obregón 2020, 348). Además, se aleja de posturas fundamentalistas que suponen "una actitud acrítica frente a la realidad" (Obregón 2020, 349) y, en última instancia, se adelantan a posteriores análisis en torno a la necesidad de convertirse a una religión para poder, de alguna u otra forma, comprenderla: esta "conversión" interior y esta participación en las otras creencias religiosas, por difíciles o imposibles, constituirían la condición de posibilidad de lograr dialogar realmente con una religión ajena a la nuestra (Obregón 2020, 354):

Entonces, la comprensión del otro como fusión de horizontes se realiza como una ampliación del propio horizonte. Esto significa que convertirse a una religión [...] no podría significar dejar el propio horizonte para trasladarse a un horizonte alterno, lo cual sería imposible porque toda comprensión se realiza desde una situación hermenéutica. La comprensión de otro horizonte de creencias religiosas supondría más bien una ampliación del propio horizonte, en el sentido en que se transforma la situación hermenéutica de quien comprende. Esto equivale a decir que la comprensión sugiere una transformación de las propias creencias religiosas, o mejor dicho, un ensanchamiento del horizonte para ganar una mayor comprensión. (Obregón 2020, 356-357).

Para cerrar, resulta oportuno señalar que el "ensanchamiento" del propio horizonte para poder comprender la religión ajena y entender que en esta puede hallarse la salvación tanto como en la nuestra, como fuese el foco de atención de nuestra investigación, radica en el abandono - o acaso constante revisión de las creencias para lograr el constante abandono- de la idolatría. Como Weil señala, basándose en la tradición hinduista, “Dios es a la vez personal e impersonal" (Weil 2011,33): personal, por cuanto lo vemos desde determinada posición cultural e histórica que, inevitablemente, nos lleva a atribuirle predicados cual si se tratase de una persona; impersonal, sin embargo, y acaso fundamentalmente, porque es de esa forma como podemos entender que ninguna de estas predicaciones puede agotar su esencia, que nuestra visión de ella siempre tendrá perspectivas parciales, "verdades explícitas que otras religiones contienen implícitamente" y viceversa (Weil 2011, 32) y que, en última instancia, la divinidad siempre querrá quedar oculta (Weil 2011,47). 


\section{$\S 3$. Conclusiones}

De manera sucinta, podemos señalar que las ideas expuestas por Simone Weil en su Carta corresponden en más de un punto a lo que Husserl señalase respecto del anquilosamiento de las construcciones teóricas humanas, inevitable dado el devenir histórico, y la necesidad de volver al fundamento vital a través de una autorreflexión fenomenológica. Dicho análisis aplica no solo a las ciencias, sino también, como vimos en Tipos, a las vivencias religiosas mismas, las cuales no requerirían de la existencia de un noúmeno, sino que podrían ser reformuladas dentro de la trascendencia propia del mundo constituido por la comunidad yoica o, como es también denominada en la quinta Meditación, "la intersubjetividad trascendental" (Husserl 2006, 142).

Todo lo anterior desemboca en la identificación de la idolatría, fundamentalismo o dogmatismo como fenómeno que surge dentro de la experiencia humana, cuya génesis puede rastrearse planteando paralelos con las crisis que surgen en otras áreas de nuestra producción teórica, tales como la ciencia. A partir de esto, entonces, podríamos concluir señalando el asentimiento que Weil daría a Husserl cuando este señalase que "[e]l Evangelio de Cristo se dirige originariamente a los individuos que anhelan la salvación y no a la nación judía" (Husserl 2012, 73).

Recibido: $26 / 05 / 2021$

Aceptado: 09/08/2021

\section{Bibliografía}

Aweita, 2018. El polémico perfil psicológico de Santa Rosa de Lima, según especialistas. La República. Recuperado de: https://aweita.larepublica.pe/ historia/1308507-santa-rosa-lima-polemico-perfil-psicologico-especialistas-religion-curiosidades

Freud, Sigmund, 2010. El malestar en la cultura. $3^{\circ}$ edición. Madrid: Alianza. 
Godina, Célida, 2011. En torno a una hermenéutica del concepto de atención en la filosofía weiliana. En: Xolocotzi, A. et al. (coords.). Ámbitos fenomenológicos de la hermenéutica. México, D. F.: Eón, pp. 215-225.

Gray, John, 2019. Siete tipos de ateísmo. $2^{\circ}$ edición. México, D. F.: Sexto Piso.

Guerra, Margarita \& Guerra, Estrella, 2017, eds. Santa Rosa de Lima: miradas desde el cuarto centenario. Lima: Publicaciones del Instituto Riva-Agüero.

Held, Klaus, 2011. La experiencia intersubjetiva del mundo. En: Ámbitos fenomenológicos de la hermenéutica, eds. Ángel Xolocotzi et al. México, D. F.: Eón, 11-28.

Husserl 1991. La crisis de las ciencias europeas y la fenomenología trascendental. Una introducción a la filosofía fenomenológica. Traducción de Jacobo Muñoz \& Salvador Mas. Barcelona: Crítica.

- 1995. Fichte's ideal of humanity. Three lectures. Traducción de James Hart. Husserlian Studies (12).

- 2000. El origen de la geometría. Traducción de Rosemary Rizo-Patrón \& José Arce. Estudios de filosofía (4).

- 2001. Analyses concerning passive and active synthesis. Lectures on transcendental logic. Traducción de Anthony Steinbock. Dordrecht: Kluwer Academic Publishers.

- 2006. Meditaciones cartesianas. Traducción de Mario Presas. $3^{\circ}$ edición. Madrid: Tecnos.

- 2012. Renovación del hombre y de la cultura. Cinco ensayos. Traducción de Agustín Serrano de Haro]. Barcelona: Anthropos.

- 2020. Introducción a la ética. Lecciones de los semestres de verano de 1920 y 1924. Traducción de Mariana Chu, Mariano Crespo \& Luis Rabanaque. Madrid: Trotta.

Martín, Juan, 2003. El fenómeno místico. $2^{\circ}$ edición. Madrid: Trotta.

Obregón, José, 2020. El problema del diálogo interreligioso desde una perspectiva hermenéutica. En: La racionalidad ampliada. Nuevos horizontes de la fenomenología y la hermenéutica, eds. Mariana Chu \& Rosemary Rizo-Patrón. Lima: Fondo Editorial PUCP, 343-367.

Otto, Rudolf, 2016. Lo santo. Lo racional y lo irracional en la idea de Dios. $3^{\circ}$ edición. Madrid: Alianza.

Rizo-Patrón, Rosemary, 2018. Sentidos de lo "Absoluto". Releyendo "Ideas I". En: El deber gozoso del filosofar. Homenaje a Miguel García-Baró, eds. Agustín Serrano de Haro et al. Salamanca: Sígueme, 107-121.

- 2020. Fenomenología y metafísica husserlianas ante un nuevo paradigma científico. En: La racionalidad ampliada. Nuevos horizontes de la fenomenología y la hermenéutica, eds. Mariana Chu \& Rosemary Rizo-Patrón. Lima: Fondo Editorial PUCP, 23-69. 
Steinbock, Anthony, 2007. Phenomenology and mysticism. The Verticality of religious experience. Bloomington: Indiana University Press.

Weil, Simone, 2007. No empecemos otra vez la guerra de Troya. En: Escritos históricos y políticos. Madrid: Trotta, 351-365.

- 2011. Carta a un religioso. Traducción de María Tabuyo \& Agustín López. $2^{\circ}$ edición. Madrid:Trotta.

- 2014. Nota sobre la supresión general de los partidos políticos. Palma de Mallorca: De Olañeta. 